\title{
UMA INTERVENÇÃO EM CONTAGEM COM DUAS CRIANÇAS SURDAS
}

\author{
Rosane da C. VARgas \\ Beatriz V. Dorneles ${ }^{* *}$
}

RESUMO: Este estudo de caso investigou se crianças surdas, filhas de pais surdos, estão em vantagem para aprender conceitos numéricos comparados com crianças surdas, filhas de pais ouvintes. Comparamos a resposta à intervenção de duas crianças de 6 anos de idade: um menino sinalizante nativo e uma menina que entrou em contato com a língua de sinais a partir dos 2 anos de idade. Ambos participaram de uma intervenção breve projetada para melhorar a compreensão da composição aditiva e o uso de procedimentos econômicos de contagem na resolução de problemas. Contrariamente às nossas expectativas, as crianças alcançaram níveis semelhantes no uso de procedimentos de contagem, na compreensão aditiva do número e também no aumento do campo numérico.

Palavras-chave: Crianças surdas. Contagem. Composição aditiva. Estratégias e procedimentos de contagem.

\section{AN INTERVENTION IN COUNTING WITH TWO DEAF CHILDREN}

ABSTRACT: This study investigated if deaf children born to deaf parents are at an advantage to learning number concepts in comparison to deaf children born to hearing parents. We compared the response

* Departamento de Técnicas e Métodos de Ensino, Pontifícia Universidade Católica. Porto Alegre (RS) - Brasil.

** Faculdade de Educação, Universidade Federal do Rio Grande do Sul. Porto Alegre (RS) - Brasil. Contato com as autoras: <bvdornel@terra.com.br>

Cad. Cedes, Campinas, v. 33, n. 91, p. 411-427, set.-dez. 2013

Disponível em <http://www.cedes.unicamp.br> 
to intervention of two six-year old children: a native-signing boy and a late-signing girl. They participated in an intervention designed to improve their understanding of additive composition and the use of economic counting strategies in problem solving. Both children achieved similar levels in the use of economic counting strategies and understanding of additive composition, as well as similar increase in their counting range. The similarities in learning by the native-signing and the late-signing children suggest that both groups may benefit from the same sort of teaching.

Key words: Deaf children. Counting. Additive composition. Counting strategies and procedures.

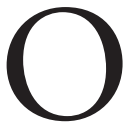

conhecimento das crianças pequenas sobre número envolve reconhecer perceptivamente, sem contar, e também aprender a contar. A contagem é a primeira ferramenta matemática cultural aprendida pelas crianças. Aprender a contar exige a observação dos princípios de contagem, a compreensão das regularidades do sistema de contagem e o uso dos números em diferentes situações para quantificar conjuntos; portanto, envolve a ligação de esquemas de raciocínio com a linguagem (RESNICK, 1989). A contagem fornece os fundamentos para o desenvolvimento das habilidades da aritmética básica. Em torno dos 5 anos de idade, a maioria das crianças ouvintes pode contar até cinco quando apontam para os objetos e começam a atender os cinco princípios da contagem (GELMAN; GALISTELL, 1978): correspondência termo a termo, na qual cada objeto contado deve ter correspondência com o nome de um numeral; ordem estável, na qual os rótulos numéricos obedecem a uma sequência invariável, cardinalidade que significa que o último numeral da sequência de uma contagem determina a quantidade de elementos do conjunto contado; irrelevância da ordem, em que não importa a ordem usada na enumeração dos objetos, desde que nenhum dos demais princípios seja violado; e abstração, que consiste na ideia de que os objetos de qualquer tipo podem ser reunidos e contados.

Temos pouca informação disponível sobre quando as crianças surdas começam a usar tais princípios. Algumas pesquisas mostram que estas crianças estão em desvantagem na aquisição dos conceitos matemáticos, se comparadas com seus pares ouvintes (GREGORY, 1995; NUNES, 2004; TRAXLER, 2000; WOOD; WOOD; HOWARTH, 1984). No domínio 
da representação numérica, sem contagem, Zarfaty, Nunes e Bryant (2004) observaram que as crianças surdas apresentam um desempenho tão bom quanto as crianças ouvintes em uma tarefa de reprodução numérica sem apresentação de modelo. Eles também descobriram que as crianças surdas têm um desempenho melhor que as ouvintes quando o conjunto a ser reproduzido foi apresentado simultaneamente de forma visual. Crianças surdas parecem aprender a contar de forma mais lenta do que as crianças ouvintes. No entanto, dentro de sua escala de contagem, as crianças surdas com idade entre 3 a 6 anos são capazes de respeitar os princípios da contagem (LEYBAERT; VAN CUTSEM, 2002). Leybaert e Van Cutsem (op. cit.) concluíram que a dificuldade não está nos procedimentos da contagem, mas na aquisição de uma sequência numérica de natureza linguística, conclusão apoiada por outro estudo (KOVORST; NUERK; WILMES, 2007). Ainda assim, as crianças surdas parecem estar em desvantagem na compreensão das regularidades do sistema numérico (NUNES, 2004) e esta desvantagem parece persistir ao longo da vida. Korvorst, Nuerk e Wilmes (op. cit.) avaliaram uma ampla gama de representaçóes numéricas (quantidade, conhecimento de fatos da multiplicação e o uso de informações da paridade) em adultos surdos sinalizantes. Eles concluíram que nesses adultos algumas representações (p. ex., a paridade) podem ser semelhantes às dos adultos ouvintes, embora automaticamente menos ativado nos surdos sinalizantes do que na população ouvinte. Estilos de ensino e de aprendizagem ineficientes, falta de motivação, o domínio da série de contagem e as diferenças idiossincráticas entre as línguas faladas e a de sinais são fatores que podem causar um atraso no desenvolvimento das habilidades matemáticas dos indivíduos surdos (LEYBAERT; VAN CUTSEM, 2002).

Por outro lado, algumas vantagens dos indivíduos surdos são relatadas em outros domínios cognitivos, tais como desvio de atenção visual (RETTENBACK; DILLER; SIRETEAUNU, 1999), detecção do movimento periférico (BAVELIER et al., 2000), velocidade da geração da imagem mental (EMMOREY; KOSSLYN, 1996), associação de palavras (MARSCHARK et al., 2004), entre outras. Então, podemos imaginar que as crianças surdas têm dificuldades nos aspectos da matemática que são dependentes da linguagem. Gregory (1998) sugere que a linguagem pode ser, em parte, responsável pelo atraso na aquisição de conceitos numéricos apresentado pelas crianças surdas, já que as palavras que fazem parte do vocabulário diário podem ter um significado matematicamente específico quando usadas. Um exemplo: um número "alto" irá se referir à quantidade ao invés da localização 
espacial física. Gregory (op. cit.) também discute a importância do papel que experiências de aprendizagem incidentais desempenham no desenvolvimento de conceitos matemáticos informais. O conhecimento informal é o conhecimento espontâneo, que se dá nas relaçóes sociais do dia a dia. Mesmo antes de entrar para a escola, as crianças vivem em um mundo rico de informações quantitativas, geométricas, de probabilidade e estimativa. Crianças surdas podem ficar fora de discussóes relacionadas ao tamanho das roupas, dos sapatos e outros, limitando assim sua exposição a oportunidades de aprendizagem matemática. Também podem não ter acesso à televisão e outras formas de comunicação que poderiam dar-lhes informação relacionada com matemática. Outro ponto importante é a falta de comunicação linguística com seus pais, irmãos e outros membros da família, bem como a sociedade em geral. Situações como comprar algo na padaria e realizar o cálculo para descobrir o troco são comuns entre crianças ouvintes e incomuns entre crianças surdas.

Ao mesmo tempo, é importante destacar que a surdez em crianças brasileiras, como em outros lugares, não é diagnosticada precocemente e, uma vez detectada, a maioria das crianças surdas tem pais ouvintes e eles precisam aprender a língua de sinais para uma comunicação adequada com seus filhos. É importante notar que algumas dessas crianças não aprendem a língua de sinais antes da escolaridade e muitos pais ouvintes não têm fluência nesta língua. Consequentemente, algumas crianças surdas têm um ambiente social restrito. Em uma tentativa de compreender os efeitos deste ambiente, Woolfe, Want e Siegal (2002) compararam dois grupos de crianças surdas ( 4 a 8 anos): 19 crianças surdas sinalizantes nativas (pais surdos sinalizantes; crianças com média de idade de 5,2 anos) e 32 crianças surdas que aprenderam a língua de sinais mais tarde (pais ouvintes; crianças com média de idade de 6,8 anos) e 40 crianças ouvintes (20 com média de idade de 3,7 anos e 20 com média de idade de 4,4 anos). O objetivo era avaliar a compreensão das crianças em representações mentais falsas ou verdadeiras de ações e sentimentos com tarefas apresentadas de forma pictórica e em sequência. Os resultados mostram que as crianças surdas sinalizantes nativas superam as crianças sinalizantes não nativas e a diferença entre ambas foi semelhante à diferença entre as crianças ouvintes de 3 e 4 anos de idade. Os autores sugeriram que os irmãos das crianças "podem proporcionar um ambiente positivo, no qual as crianças estão expostas a falar sobre estados mentais que os alertam para a possibilidade de que as crenças podem ser diferentes da realidade" (WOOLFE; WANT; SIEGAL, 2003, p. 345). Estes autores argumentam que crianças surdas sinalizantes não 
nativas não participam da comunicação sobre estados mentais com seus pais e irmãos, pela sua falta de uma linguagem comum, ao passo que crianças surdas nativas participam com maior frequencia. Apesar do fato desses autores não terem avaliado conceitos de números, podemos supor que essa comunicação também seria importante para tais conceitos.

Um estudo recente (KRITZER, 2009) confirmou que as crianças surdas, antes do início da educação formal, têm dificuldades na contagem em relação às crianças ouvintes e já estão em desvantagem em relação aos conceitos matemáticos informais. Embora Kritzer (op. cit.) não analise se as diferenças entre crianças surdas estavam relacionadas a exposição precoce à lingua de sinais, seu estudo contém informaçôes suficientes para permitir o exame da relação entre audição dos pais e os resultados das crianças em matemática. Dos 29 participantes de sua pesquisa, 17 crianças tinham pelo menos um dos pais surdos, cinco crianças foram classificadas como tendo habilidade superior em matemática dentro do grupo, dez com habilidade média, duas com habilidade inferior; 12 crianças tinham pais ouvintes, e uma foi classificada com alta habilidade em matemática, seis com habilidade média e cinco com habildade inferior. Assumindo uma ordenação, Kendall's Tau mostra, para esta distribuição de escores, uma significativa associação entre a audição dos pais ( $\mathrm{T}=2,26 ; \mathrm{p}=0,02)$ e habilidade matemática. No entanto, esta associação pode ser por outros fatores, como a diferença de QI ou a exposição precoce à escolarização. Kritzer (2009) também investigou a mediação em matemática informal, em famílias de seis crianças surdas com idade entre cinco e seis anos. A opção por essa faixa etária se deu pelo fato de que, nesta idade, as crianças ainda não tinham recebido educação formal. Destas seis crianças, três tinham pais surdos e usavam a Língua de Sinais Americana, enquanto as outras três eram filhas de pais ouvintes, sendo que a comunicação era em inglês oral, com apoio de alguns sinais. As crianças surdas que tinham a oportunidade de usar a língua de sinais tiveram um desempenho melhor em Matemática do que as outras três, que tinham pais ouvintes e pouco utilizavam a língua de sinais. Esse estudo, no entanto, concluiu que, embora as crianças surdas com pais surdos tivessem um desempenho significativamente melhor do que os participantes com os pais ouvintes no teste de matemática utilizado, esse desempenho melhor não foi suficiente para colocá-las em um posto mais alto do que a média de crianças ouvintes. Até onde sabemos, não há estudos comparando crianças surdas com pais ouvintes e crianças surdas com pais surdos, em uma situação de intervenção em aprendizagem matemática. 
Esta pesquisa aborda um estudo de caso que busca investigar se as crianças surdas filhas de pais surdos estão em vantagem para aprender conceitos numéricos, se comparadas com crianças surdas, filhas de pais ouvintes. Investigamos a composição aditiva do número e a melhoria no uso de procedimentos econômicos de contagem na resolução de problemas. Entendemos que o conhecimento da composição aditiva vem acompanhado do conhecimento matemático informal, que ocorre nas relações sociais fora da escola, em ambientes não intencionais, não sistematizados e organizados, no sentido da educação escolar. As crianças aprendem matemática informal na família, com os amigos, com irmãos, assistindo à televisão ou brincando, antes de chegar à escola. Para Baroody (2005), a matemática informal das crianças é um recurso fundamental entre o seu conhecimento intuitivo, que está baseado na percepção direta da realidade, e os conhecimentos abstratos, que se iniciam na educação formal. Com base na concepção de que os conceitos são adquiridos e automatizados de forma progressiva, e organizados através de esquemas que os ampliam constantemente, interrelacionando-os com conjuntos de situações em rede, entende-se que o conhecimento intuitivo da matemática é uma base para a aprendizagem da matemática formal. É possível que as crianças surdas, filhas de pais ouvintes, tenham dificuldades para essa construção, devido ao fato de que, em muitas das relações familiares, não houve comunicação suficiente para que a criança interagisse com esses conhecimentos, ou esta comunicação se deu tardiamente. Um dos conceitos básicos a ser construído é o de composição aditiva. Esta "é uma invariável dos números, significando que qualquer número n pode ser decomposto em dois outros que vêm antes dele na lista ordinal dos números, de tal modo que estes dois somam exatamente n" (NUNES; BRYANT, 1997, p. 57), ou seja, é a compreensão de que qualquer número é composto pela soma de várias unidades de tamanhos diferentes. Por exemplo, em nosso sistema de numeração decimal, de base dez, o número 124 é igual à soma de uma unidade de cem, duas unidades de dez e quatro unidades de quatro.

A compreensão de composição aditiva em crianças surdas foi avaliada por Nunes e Moreno (1998) através de tarefa de compra de diferentes objetos, sempre usando valores numéricos dentro da faixa de contagem de cada criança. As autoras compararam 80 crianças surdas com 69 crianças ouvintes, as mesmas que foram avaliadas em outro estudo sobre unidades de diferentes tamanhos, para avaliar a construção da composição aditiva. As autoras relatam que crianças surdas e ouvintes, que falharam na tarefa de diferentes tamanhos 
de unidades, não executaram bem os itens de composição aditiva e que crianças ouvintes de 7 ou 8 anos de idade não têm dificuldades com a composição aditiva na tarefa de compra. Ao contrário das crianças ouvintes, apenas $25 \%$ das crianças surdas com idade de 8 anos e 6 meses acertaram todas as tarefas. O desempenho das crianças surdas foi significativamente melhor, na medida em que avançavam na escolarização. Não houve diferença no desempenho das crianças em relação ao tipo de comunicação usada. Crianças ouvintes parecem usar algumas pistas da linguagem oral. Ao testar essas pistas com crianças surdas em língua oral e em língua de sinais, foi observado que as crianças surdas não utilizam esse recurso (NUNES, 2004), nem em linguagem de sinais.

Outro aspecto importante da construção numérica inicial são os procedimentos de contagem. Sabe-se que os principais procedimentos de contagem descritos na literatura são o counting-all - ou seja, contar todos e o counting-on - contar na sequência. Geary (2004) e Geary et al. (2000) indicam que há uma evolução nos procedimentos usados pelas crianças para contar: (a) contar todos, com auxílio dos dedos ou material concreto - a criança necessita representar todas as parcelas. No exemplo $2+3$, a criança conta "um, dois", com uma mão, e "um, dois, três", com a outra mão, e só depois inicia a contagem total "um, dois, três, quatro, cinco"; (b) contar todos a partir da primeira parcela - a criança inicia a contagem pela primeira parcela, independentemente da magnitude do número; (c) contar todos a partir do maior - a criança inicia a contagem pela parcela maior. No exemplo $2+3$ a criança faz a contagem: "um, dois, três... quatro, cinco"; (d) contar a partir do primeiro - no cálculo $2+3$ a criança retém na memória o primeiro que é dois e conta "três, quatro, cinco"; e (e) contar a partir do maior implica a criança perceber que é mais econômico iniciar a contagem pelo número maior. No exemplo $2+3$, ela retém na memória o três e conta "quatro, cinco". Tais procedimentos estão descritos aqui em uma ordem hierárquica de eficiência. Quanto mais a criança avança, mais ela vai usando procedimentos econômicos, possibilitando chegar ao uso de procedimentos avançados, como o desenvolvimento da representação desses fatos na memória (GEARY, 2004). Isso possibilita a recuperação direta dos fatos da memória de longo prazo, ou seja, no exemplo $2+3$, a criança responde rapidamente que é igual a cinco, sem o uso de outro recurso. Ou ainda, permite a decomposição que envolve reconstruir a resposta baseada na recuperação de uma soma parcial, ou seja, na soma $2+3$, a criança recupera uma soma conhecida $2+2$ e acrescenta 1 . Essas duas últimas estratégias são mais rápidas e eficientes. 
Nunes e Bryant (1997) destacam que o avanço do uso do procedimento de contar todos para o procedimento de contar na sequência, contar a partir de, representa um crescimento no entendimento do sistema decimal. A criança que usa o procedimento de contar todos na resolução da operação $5+2=7$ conta: $1,2,3,4,5,6,7$, ou seja, conta todos. Já a que usa o procedimento de contar a partir do maior, para a mesma situação problema, conta 6,7 , uma contagem mais rápida e eficiente. Sabe-se que as crianças ouvintes vão progressivamente substituindo os procedimentos menos eficientes pelos mais eficientes, mas sabe-se muito pouco a respeito de como as crianças surdas o fazem e, menos ainda, se o momento da aquisição da linguagem de sinais é um fator importante para determinar a rapidez com que se dá o avanço no desenvolvimento de tais procedimentos. Esse é o tema central da pesquisa que descrevemos a seguir.

\section{Método}

A hipótese principal da pesquisa é que a criança surda, filha de pais surdos, sinalizante nativo, desenvolveria uma compreensão das regularidades do sistema de contagem e da composição aditiva mais rapidamente do que a criança surda, filha de pais ouvintes, sinalizante não nativo, devido à sua experiência com a língua de sinais desde o nascimento.

Para testar a hipótese, nós comparamos as respostas à intervenção de duas crianças de 6 anos de idade: um menino sinalizante nativo, aqui denominado de João, e uma menina sinalizante não nativa, aqui denominada de Maria. Ambos tinham perda auditiva neurossensorial bilateral de severa a profunda e não tinham implante coclear. As crianças tinham o mesmo QI (WISC-R) e frequentavam o primeiro ano do ensino fundamental. Ambas estudavam em escola especial para crianças surdas, tendo professores ouvintes e surdos nas duas diferentes escolas. A comunicação na família da criança sinalizante nativa se deu desde o nascimento através da Língua Brasileira de Sinais (Libras), já que seus pais são surdos. Na família da criança sinalizante não nativa a comunicação acontece através da língua oral. Segundo a informação da mãe, o pai sabe pouco de Libras. A mãe tem uma boa fluência nesta língua, e sempre que a escola oferece cursos nesta modalidade ela participa.

Utilizamos um protocolo de avaliação constituído pela Tarefa de Compra (NUNES; BRYANT, 2007); pelos Princípios de Contagem (GELMAN; 
GALISTEL, 1978) e pela parte inicial do teste de procedimentos de contagem de Geary, Hamson e Hoard. (2000), adaptado por Corso (2008) e com alterações da investigadora, em função das características das crianças investigadas. Consideramos o estudo de caso como uma parte da pesquisa etnográfica e, na pesquisa que descrevemos a seguir, foi focado no programa de intervenção e seus resultados, em uma exploração, em profundidade, do processo observado.

Realizamos três avaliações de ambas as crianças: o pré-teste, antes do início da intervenção pedagógica, o teste intermediário ao final da última intervenção, e um pós-teste três meses após a última intervenção. A avaliação foi composta por oito Tarefas de Compra (NUNES, 2004), com objetos a serem comprados com cédulas de um, dois e cinco reais, e dez situações de adição para avaliação de procedimentos de contagem. Após a primeira avaliação, na própria escola de cada um, as crianças participaram de uma breve intervenção de oito sessões implementadas ao longo de quatro semanas, para estimular sua compreensão da composição aditiva, que esperávamos que ampliasse a contagem e estimulasse o uso mais econômico de procedimentos de contagem na resolução de problemas aditivos. Cada criança trabalhou em sessões individuais com uma professora experiente na educação de surdos (primeira autora). Durante a intervenção, as crianças costumavam contar para representar espacialmente as quantidades apresentadas e para "comprar" os objetos em um "supermercado". Após as oito sessões as crianças foram reavaliadas. $\mathrm{Na}$ tabela a seguir podemos ver as atividades propostas às crianças:

\section{Tabela 1}

\begin{tabular}{|c|c|c|}
\hline OBJETIVOS & \multicolumn{1}{|c|}{ SITUAÇÕES DIDÁTICAS } & MATERIAL \\
\hline Composição aditiva & $\begin{array}{l}\text { 1) Jogo do supermercado: um conjun- } \\
\text { to de pequenas coisas que deveriam } \\
\text { ser comprados em um supermercado. }\end{array}$ & $\begin{array}{l}\text { Bolas, doces, brinquedos, ma- } \\
\text { terial escolar, esmalte cédulas } \\
\text { de valores diferentes. }\end{array}$ \\
\hline Composição aditiva & $\begin{array}{l}\text { 2) Jogo do cartão: os cartōes com os } \\
\text { pontos deveriam ser organizados para } \\
\text { formar um número mostrado em ou- } \\
\text { tro cartão. }\end{array}$ & $\begin{array}{l}\text { Cartôes com pontos (um, } \\
\text { dois, três, quatro e cinco pon- } \\
\text { tos) e cartôes com numerais. }\end{array}$ \\
\hline
\end{tabular}

Cad. Cedes, Campinas, v. 33, n. 91, p. 411-427, set.-dez. 2013 


\begin{tabular}{|c|c|c|}
\hline Composição aditiva & $\begin{array}{l}\text { 3) Jogo de cartôes transparentes: as } \\
\text { crianças escolhiam cartôes trans- } \\
\text { parentes marcados com pontos e } \\
\text { colocavam uns sobre os outros para } \\
\text { atingir o valor de um número pré-de- } \\
\text { finido, no maior número possível de } \\
\text { combinações. }\end{array}$ & $\begin{array}{l}\text { Cartões transparentes com } \\
\text { pontos (um, dois, três, qua- } \\
\text { tro, cinco) e cartôes com nu- } \\
\text { merais. }\end{array}$ \\
\hline $\begin{array}{l}\text { Procedimentos de } \\
\text { contagem }\end{array}$ & $\begin{array}{l}\text { 4) Jogo "Fecha a caixa": as crianças } \\
\text { lançavam os dados e fechávamos } \\
\text { números sob a "janela" que cobre os } \\
\text { números formando o total mostrado } \\
\text { nos dados. }\end{array}$ & $\begin{array}{l}\text { Jogo do "Fecha a caixa" e } \\
\text { dois dados. }\end{array}$ \\
\hline $\begin{array}{l}\text { Procedimentos de } \\
\text { contagem }\end{array}$ & $\begin{array}{l}\text { 5) Na boca do sapo: crianças joga- } \\
\text { vam os dados e colocavam, na boca } \\
\text { do sapo, o número de balas que cor- } \\
\text { respondia ao total mostrados nos } \\
\text { dados. }\end{array}$ & $\begin{array}{l}\text { Um sapo com a boca aberta, } \\
\text { semelhante a um saco e algu- } \\
\text { mas balas. }\end{array}$ \\
\hline $\begin{array}{l}\text { Procedimentos de } \\
\text { contagem }\end{array}$ & $\begin{array}{l}\text { 6) O segredo das caixas. Duas caixas } \\
\text { foram apresentados às crianças. Na } \\
\text { primeira, foram colocadas algumas } \\
\text { fichas que as crianças já haviam con- } \\
\text { tado e a caixa foi fechada. O investi- } \\
\text { gador fazia o mesmo coma segunda } \\
\text { caixa e perguntava quantas fichas } \\
\text { havia nas duas caixas. }\end{array}$ & $\begin{array}{l}\text { Duas caixas com tampas e } \\
\text { material de contagem. }\end{array}$ \\
\hline $\begin{array}{l}\text { Procedimentos de } \\
\text { contagem }\end{array}$ & $\begin{array}{l}\text { 7) O fantoche que comia balas. O } \\
\text { investigador colocava balas na boca } \\
\text { do fantoche e a criança contava. A } \\
\text { boca do fantoche era fechada. O in- } \\
\text { vestigador dava mais balas ao fanto- } \\
\text { che e a criança novamente contava. } \\
\text { Ao final, devia dizer quantas balas o } \\
\text { fantoche comeu ao todo. }\end{array}$ & Um fantoche e balas. \\
\hline $\begin{array}{l}\text { Adição de fatos } \\
\text { básicos com Libras }\end{array}$ & $\begin{array}{l}\text { 7) Adição de fatos básicos. As crian- } \\
\text { ças olhavam os fatos básicos escritos } \\
\text { nos cartōes e usavam dedos e ma- } \\
\text { terial de contagem para resolver a } \\
\text { operação. }\end{array}$ & $\begin{array}{l}\text { Cartões com fatos básicos } \\
\text { simples. }\end{array}$ \\
\hline
\end{tabular}


Durante as oito sessões de trabalho, propusemos três ou quatro dessas diferentes situações didáticas em cada uma delas, com uma variedade de materiais. No final das oito sessōes, as crianças foram avaliadas com o mesmo protocolo que usamos na primeira sessão de avaliação.

Os resultados estão resumidos nos dois gráficos apresentados a seguir.

\section{Gráfico 1}

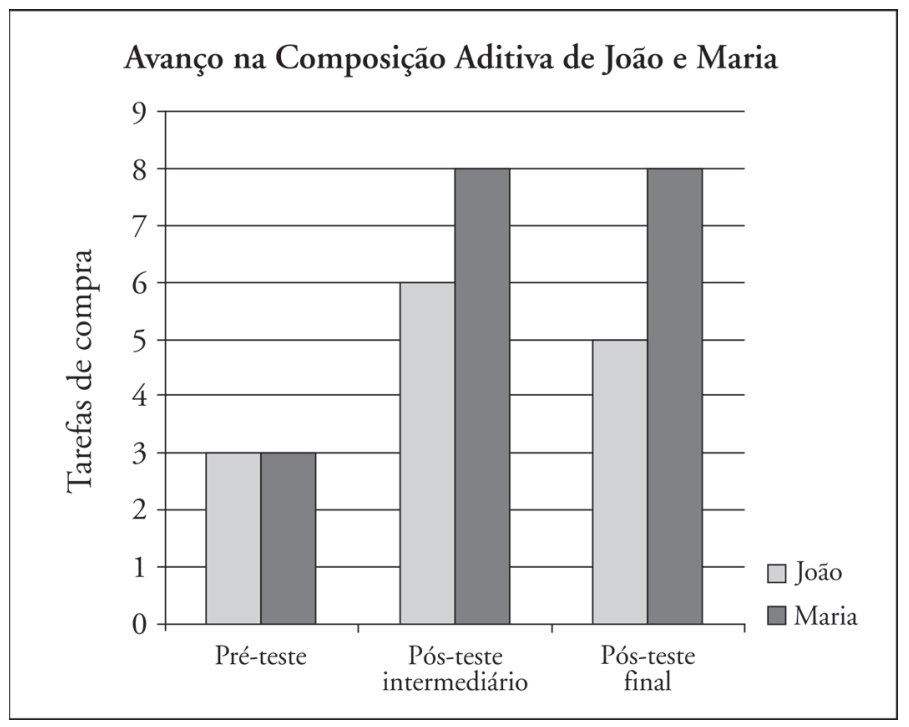

O gráfico 1 mostra a evolução de ambas as crianças na Tarefa de Compra desde o pré-teste até o pós-teste final após três meses da última intervenção. Nota-se que no pós-teste final, Maria manteve o avanço que já tinha apresentado no pós-teste intermediário. João teve uma leve queda em relação ao teste intermediário, o que nos faz questionar a manutenção de sua aprendizagem.

No gráfico 2, na próxima página, observamos a evolução dos procedimentos de contagem das duas crianças.

Ao comparar o uso de procedimentos de contagem das duas crianças, verifica-se que, do pré-teste ao pós-teste, houve uma pequena variação de desempenho entre os dois. Ambos iniciaram as intervençôes com 100\% de 
uso do procedimento de contar todos. Após a intervenção, pode-se observar que João teve um avanço de $60 \%$, somando os $40 \%$ de avanço no procedimento de recuperação de fatos da memória, mais $20 \%$ do procedimento de contar a partir de. Já Maria teve um avanço de $70 \%$, pois teve $40 \%$ no procedimento de recuperação de fatos da memória e mais $30 \%$ no procedimento de contar a partir de.

\section{Gráfico 2}

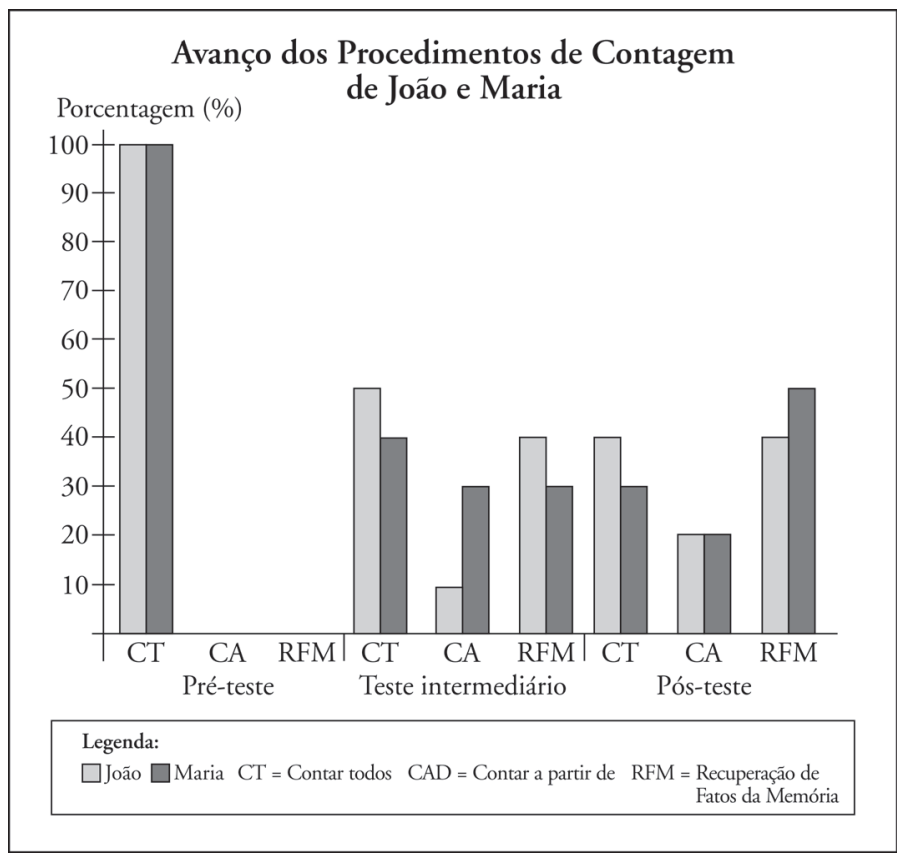

É importante salientar uma das dificuldades que se impôs para ambas as crianças: a não correspondência direta entre a representação de alguns algarismos em Língua Brasileira de Sinais (Libras), o seis, por exemplo, e a sua respectiva quantidade. Maria, ao ser solicitada a adicionar seis mais um, sinalizava seis, com sua mão de dominância, mais o um, na outra mão e, na hora de juntar, utilizava o procedimento de contar todos para confirmar 
a quantidade seis. Ao fazer isso, sua mão saía da configuração de seis. Ela abria-a, contava até cinco e percebia que faltava algo. Então, utilizava material de contagem para realizar a operação. Pode-se pensar que Maria fez uso da Libras para expressar seu pensamento e representou, através do material concreto, demonstrando que lhe faltava transformar esta representação em simbolismo matemático (VERGNAUD, 1996). Possivelmente, esta situação signifique um obstáculo para adição inicial e para o uso de procedimentos mais econômicos, em virtude da estrutura dos números iniciais em Libras.

Nas situações de intervenção didática de adição de fatos básicos com Libras, João e Maria foram capazes de recuperar quase todos os fatos básicos da memória. Tal situação não ocorreu quando os mesmos fatos foram apresentados em cartelas, nos testes de avaliação. Determinados fatos básicos, que são facilmente identificados pela sua representação com todos os dedos, tais como $4+2$ ou $3+2$, parecem ser mais facilmente recuperáveis da memória do que os que envolvem cinco ou seis, por exemplo, que não têm uma representação de mão diretamente relacionada com a quantidade expressa.

Contrariamente às nossas expectativas, houve mais semelhanças do que diferenças nas aprendizagens das crianças. Ambas as crianças avançaram no uso de procedimentos mais econômicos de contagem (de contar todos para contar a partir de, e recuperação de fatos na memória) e na compreensão da composição aditiva; a contagem da série numérica também se ampliou em níveis semelhantes. Ser nativo em língua de sinais não foi um fator crucial para determinar o quanto as crianças se beneficiaram da intervenção. É importante sublinhar que esta afirmação só pode ser feita para esta situação proposta. Com efeito, esta é uma limitação dos estudos de caso. A sua possibilidade de generalização é muito limitada, pois está restrita a situações semelhantes ao caso que originou a pesquisa. Na nossa pesquisa, com duas crianças, nas condições de intervenção propostas, pode-se afirmar que ambas tiverem uma evolução muito semelhante e que o momento de aquisição da linguagem não foi um fator facilitador de sua evolução na aquisição do conceito numérico da composição aditiva, nem na evolução para a aquisição de procedimentos mais econômicos de contagem.

\section{Conclusões}

Há uma forte relação entre desenvolvimento da composição aditiva e o desempenho matemático em testes padronizados sobre o conhecimento 
matemático de crianças surdas (NUNES, 2004). Crianças ouvintes em geral adquirem tal conhecimento informalmente, antes de entrar para a educação formal, e, com tal conceito, constroem uma base sólida para aprendizagem de números.

O estudo converge com investigações que mostraram que os processos no desenvolvimento de contagem são semelhantes em crianças surdas e crianças ouvintes. Podemos dizer que os processos no desenvolvimento de contagem também são semelhantes nas duas crianças que participaram da pesquisa e vão na mesma direção dos estudos sobre aquisição de procedimentos de contagem em crianças ouvintes. $\mathrm{O}$ estudo também se alinha com pesquisas anteriores que indicaram que as intervenções breves podem ajudar as crianças surdas a melhorar a sua compreensão do sistema de numérico (NUNES et al., 2009). A aprendizagem semelhante entre uma criança surda filha de surdos e uma criança surda filha de ouvintes indica que ambos puderam se beneficiar do mesmo tipo de ensino para melhorar suas habilidades de contagem e compreensão da composição aditiva. Este é um resultado importante para a educação, uma vez que ressalta as necessidades de intervenção precoce do conhecimento do número de crianças surdas e mostra que essas intervenções não necessitam ser diferenciadas em função da audição dos pais ou do tempo de aquisição da linguagem de sinais.

É importante destacar que propostas de intervenção como a que utilizamos também são necessárias para ensinar os pais a mediar os primeiros conceitos matemáticos de suas crianças nas relações informais. Nesta pesquisa, trabalhou-se um total de quatro horas com cada criança e foi possível observar um avanço no conceito de composição aditiva e nas habilidades de contagem. Sabe-se que uma intervenção direta individual com as crianças poderá resultar em avanços mais rápidos. Porém, as escolas para crianças surdas, que têm, em geral, poucos alunos por turma, no Brasil, podem e devem pensar em pequenas intervenções, focadas nas necessidades dos alunos, e trabalhar em pequenos grupos em sala de aula. A possibilidade de interação com mais colegas, diferente da nossa proposta de intervenção investigativa, poderá ampliar o avanço das crianças. O programa de intervenção, conforme foi proposto, demonstrou ser eficiente mesmo sendo breve.

Sabe-se que as primeiras experiências de contagem acontecem muito precocemente, exigindo das famílias a necessidade de envolver as crianças surdas em ambientes de linguagem ricos em matemática informal, seja qual for a linguagem. Nossa pesquisa indiretamente retoma o papel das escolas na 
ação com as famílias, no sentido de ajudá-las a compreender a importância dos primeiros conceitos matemáticos e a necessidade de criar ambientes estimuladores para seus filhos, de forma semelhante à estimulação que é feita com crianças ouvintes. Isto não significa envolver os pais em situações didáticos-pedagógicas do ensino de Matemática, mas acolher as famílias para a conscientização da importância do conhecimento matemático inicial. Significa esclarecer as famílias que criança surda tem a mesma necessidade de experienciar um ambiente matematizado que as outras crianças, ambiente que lhes oportunize participar de jogos e situações simbólicas matemáticas. Isto pode ocorrer, por exemplo, na autonomia para fazer compras, no ato de jogar com amigos surdos e ouvintes, na organização de grupos com a mesma quantidade de alimentos, pois, nestas trocas, a criança é envolvida com adição, subtração e outros conceitos matemáticos. Durante a sua formação, os professores de crianças surdas poderão também beneficiar-se de cursos que se concentrem em suas habilidades para criar ambientes de aprendizagem que estimulem o desenvolvimento cognitivo em matemática de crianças surdas.

Duas limitaçōes do trabalho devem ser apontadas. Em primeiro lugar, o estudo de caso é um método de pesquisa com limitadas possibilidades de generalização, circunscritas a condições semelhantes às do estudo original. Portanto, nosso estudo tem possibilidades limitadas de generalização. Em segundo lugar, apesar de ter sido feita na escola, tal intervenção foi feita fora da sala de aula, a fim de que se pudesse observar somente o desempenho das crianças envolvidas. De qualquer forma, nossa conclusão ressalta que, independente do momento de aquisição da linguagem de sinais, as crianças surdas precisam ser atendidas nas suas necessidades específicas para que possam construir os primeiros conceitos numéricos tão cedo quanto as crianças ouvintes, conceitos estes que serão a base para toda a construçãoo numérica posterior.

\section{Referências}

BAROODY, A.J. El pensamiento matemático de los niños. Um marco evolutivo para maestros de preescolar, ciclo inicial y educación especial. Madrid: Machado Livros, 2005.

BAVELIER, D. et al. Visual attention to the periphery is enhanced in congenitally deaf individuals. Journal of Neuroscience, n. 20, p. 1-6, 2000. 
CORSO, L. Dificuldades na leitura e na escrita: um estudo dos processos cognitivos em alunos da $3^{\mathrm{a}}$ a $6^{\mathrm{a}}$ série do ensino fundamental. 2008. $218 \mathrm{f}$. Tese (Doutorado em Educação) - Programa de Pós-Graduação em Educação, Universidade Federal do Rio Grande do Sul, Porto Alegre.

EMMOREY, K.; KOSSLYN, S. Enhanced image generation abilities in deaf signers: A right hemisphere effect. Brain and Cognition, n. 32, p. 2844, 1996.

GEARY, D.C. Mathematical and learning disabilities. Journal of Learning Disabilities, Thousand Oaks, v. 37, n. 1, p. 4-15, Jan. 2004.

GEARY, D.C.; HAMSON, C.O.; HOARD, M.K. Numerical and arithmetical cognition: a longitudinal study of process and concept deficits in children with learning disabilities. Journal of Experimental Child Psychology, San Diego, n. 77, p. 236-263, 2000.

GELMAN, R.; GALLISTEL, C.R. The child's understanding of number. Harvard, Mass.: Harvard University Press, 1978.

GREGORY, S. Young deaf children and their families. Cambridge, Mass.: Cambridge University Press, 1995.

KOVORST, M.; NUERK, H.-C.; WILMES, K. The hands have it: number representations in adult deaf signers. Journal of Deaf Studies and Deaf Education, v. 12, n. 3, p. 362-372, 2007.

KRITZER, K. Barely started and already left behind: a descriptive analysis of the mathematics ability demonstrated by young deaf children. Journal of Deaf Studies and Deaf Education, n. 14, p. 409-421, 2009.

LEYBAERT, J.; VAN CUTSEM, M.-N. Counting in sign language. Journal of Experimental Child Psychology, n. 81, p. 482-501, 2002.

MARSCHARK, M. et al. Organization and use of the mental lexicon by deaf and hearing individuals. American Annals of the Deaf, n. 149, p. 5161, 2004.

NUNES, T. Teaching mathematics to deaf children. London: Whurr; Whiley, 2004.

NUNES, T.; BRYANT, P. Crianças fazendo matemática. Porto Alegre: Artmed, 1997. 
NUNES, T. et al. Deaf children's informal knowledge of multiplicative reasoning. Journal of Deaf Studies and DeafEducation, n. 14, p. 260-277, 2008.

RESNICK, L.B. Developing mathematical knowledge. American Psychologist, v. 44, n. 2, p. 162-169, 1989.

RETTENBACK, R.; DILLER, G.; SIRETEAUNU, R. Do deaf people see better? Texture segmentation and visual search compensate in adult but not in juvenile subjects. Journal of Cognitive Neuroscience, n. 11, p. 560-583, 1999.

TRAXLER, C.B. The Stanford Achievement Test, 9th Edition: National norming and performance standards for deaf and hard-of-hearing students. Journal of Deaf Studies and Deaf Education, n. 5, p. 337-348, 2000.

VERGNAUD, G. A Teoria dos Campos Conceituais. In: BRUN, J. Didática das matemáticas. Lisboa: Instituto Piaget, 1996. p.155-191.

WOOD, D.; WOOD, H.; HOWARTH, P. The mathematical achievements of deaf children from different educational environments. British Journal of Educational Psychology, n. 54, p. 254-264, 1984.

WOOLFE, T.; WANT, S.C.; SIEGAL, M. Sign posts to development: theory of mind in deaf children. Child Development, n. 73, p. 768-778, 2002.

WOOLFE, T.; WANT, S.C.; SIEGAL, M. Siblings and theory of mind in deaf native signing children. Journal of Deaf Studies and Deaf Education, v. 8, n. 3, p. 340-347, 2003.

ZARFATY, Y.; NUNES, T.; BRYANT, P. The performance of young deaf children in spatial and temporal number tasks. Journal of Young Deaf Studies and Deaf Education, n. 9, p. 315-326, 2004.

Recebido em 30 de maio de 2013.

Aprovado em 30 de setembro de 2013. 